\title{
Semblanza de Phil C. Weigand Moore (1937-2011)
}

\section{Juan Rodrigo Esparza}

CEQ-EL COLEGIO DE MICHOACÁN

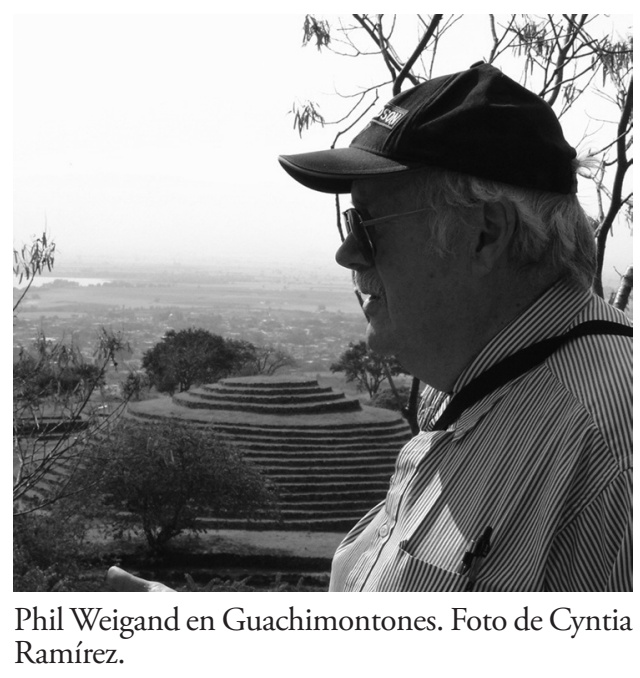

1 día 3 de septiembre de 2011, en la ciudad de Guadalajara, aconteció el sensible fallecimiento del doctor Phillip Clayton Weigand Moore, decano de nuestro Centro de Estudios Arqueológicos de El Colegio de Michoacán. Hombre visionario y explorador del siglo xxi que dejó huella en distintas ramas del conocimiento científico y antropológico. Su visión tan particular del mundo constituía una de sus más elocuentes virtudes, ya que le permitía analizar desde diferentes puntos de vista las disciplinas que eran su pasión: la etnografía, la arqueología, la historia y la antropología.

El doctor Weigand nació en Nebraska, Estados Unidos, un 2 de diciembre de 1937, hijo de una familia de inmigrantes alemanes. Se casó con Acelia García Anguiano con quien tuvo una hija Celia Imelda (Nena), cuatro nietos, además de tres bisnietos. Acelia fue su guía y 
la más entrañable colaboradora de todas sus investigaciones en México tanto de campo como de gabinete. Esta mancuerna constituiría quizá la parte más profunda de amor por la historia de Jalisco, que transformó a final de cuentas los textos de historia y cultura regional del estado.

Los estudios del doctor Weigand empezaron por los años cincuenta en la Universidad de Indiana, su licenciatura, enmarcada por la historia y la arqueología clásica bajo la batuta del doctor John Snyder, significó el trascender óptimo para crear su tesis sobre historiografía. Posteriormente, Weigand realiza en la Universidad del Sur de Illinois en Carbondale su grado de maestría en antropología en el año de 1965. De aquí su paso hacia el doctorado, fructífero por los profesores que influenciaron su obra años después, Pedro Armillas, J. Charles Kelley, Carroll L. Riley, Walter Taylor, entre otros. Su tema, que lo atrajo a México, fue un estudio etnográfico sobre el modo de vida de los huicholes de Nayarit y Jalisco.

Aunque sus estudios profesionales eran muy diversos, incluía temas etnográficos relacionados con la interpretación del paisaje, la historia de la Segunda Guerra Mundial, el fascismo en la Italia de Mussolini, entre otros. Los últimos 30 años de su vida, junto con Acelia su esposa, se dedicó a realizar el proyecto que lo enmarcó de por vida en letras doradas dentro la arqueología mexicana, que fue el estudio del sitio arqueológico de Guachimontones y la arqueología de la región centro de Jalisco.

Este proyecto que empezó en los años sesenta constituye, hasta la actualidad, el estudio arqueológico más importante del Occidente mexicano, debido principalmente al hallazgo de una nueva pieza en el gran rompecabezas mesoamericano, la ecúmene, como él la llamaba; el descubrimiento de una nueva civilización antes desconocida, que contribuyó no sólo a entender que en el Occidente de México existían sociedades complejas a principios de la era cristiana, dio lugar a la relación entre esta región de Mesoamérica y las culturas ya descubiertas en el centro y norte de México. Así también, puso en el mapa la arquitectura de Guachimontones como otra contribución al repertorio mundial de la arquitectura antigua. Pero, quizá, el logro mayor fue que, años después de su descubrimiento, para el 2006, los libros 


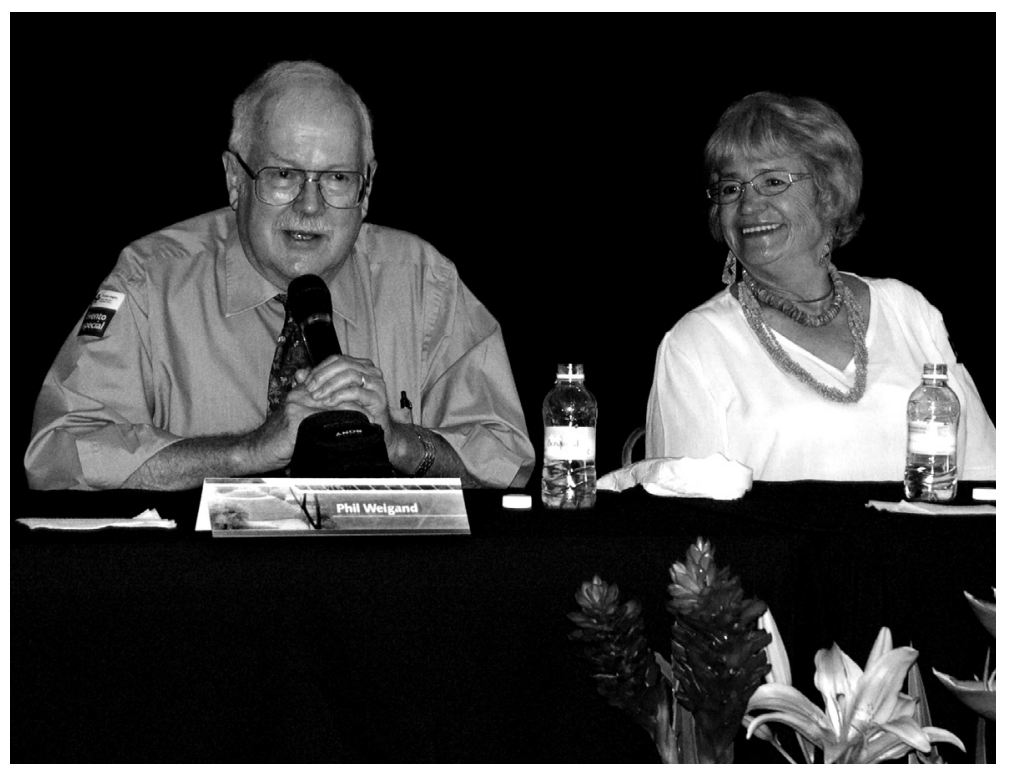

Phil Weigand y Acelia García de Weigand. Foto de John Pint.

de texto del estado de Jalisco, dentro de las culturas antiguas de México, ya hablaban de lo que se llamaría la Tradición Teuchitlán como otro icono para el estado de Jalisco, además del mariachi y el tequila.

No hay que olvidar libros tan importantes en su trayectoria científica que hasta la fecha son libros de cabecera para la antropología y la arqueología regional, como son: Tenamaxtli y Guaxicar: las raices profundas de la rebelión de Nueva Galicia (1996); Evolución de una civilización prehispánica: arqueología de Jalisco, Nayarit y Zacatecas (1993); y Tradición Teuchitlán (2008), obras editadas en El Colegio de Michoacán y algunas con ediciones agotadas.

Su paso por Relaciones. Estudios de Historia y Sociedad

Una de las revistas consentidas del doctor Weigand para publicar sus trabajos fue Relaciones. Estudios de Historia y Sociedad de El Colegio de Michoacán, lo cual podemos constatar por sus nueve artículos publicados desde 1995 hasta el 2011. 
Los temas son diversos y variados, pero los podemos conjuntar en tres grupos principales, comenzando con el tema de la arqueología con "El Qanat de La Venta: sistemas hidráulicos de la época colonial en el centro de Jalisco" (Beekman et al., 1995) donde se documenta un sistema de acueducto subterráneo de origen árabe que fue importante para la economía agrícola de la región centro de Jalisco. Posteriormente, publica "Adela Breton y los inicios de la arqueología de México" (Weigand y Williams 1997), el artículo constituye una reivindicación del lugar que merece la exploradora francesa en el inicio de la arqueología sistemática del Occidente de México, sus trabajos, como los autores comentan, fueron esenciales para reconocer de manera general la relación entre las figurillas de cerámica con las tumbas de tiro, observó también la ocurrencia de los yacimientos de obsidiana y su relación con las culturas de la región y, sobre todo, dio a conocer la presencia de las estructuras circulares que años después se conocerían como Guachimontones.

Así también, en el artículo "San Aguebaud, Claudius y la arqueología” (Weigand 2008) desarrolla las limitaciones que la arqueología contiene y su dependencia de ésta con la historia, principalmente en el uso de la analogía que proviene del registro histórico y etnográfico y no en sí misma.

Quizá uno de los artículos más significativos es "La antigua ecumene mesoamericana: ¿Un ejemplo de sobreespecialización?”' (Weigand 2000), ya que constituye un parteaguas en la irrupción de una metodología, no tanto basada en la arqueología, sino apoyada sobre la antropología y la historia tratando de entender el desarrollo de las civilizaciones de Mesoamérica en comparación con el resto del mundo. En este sentido, analiza la falta de animales domésticos en gran escala y la especialización en el dominio de plantas cultivables que dieron una pauta especial y única a esta parte del continente americano. La llegada de las bestias rumiantes después de la conquista implicó un cambio completo en el esquema central de desarrollo.

\footnotetext{
${ }^{1}$ Premio al mejor artículo del periodo Prehispánico por parte del Comité Mexicano de Ciencias Históricas en el año 2000.
} 
El otro conjunto de artículos referidos propiamente a la etnohistoria comienzan con "El fin de un mundo y la formación de uno nuevo. Ensayo-reseña de sociedades en construcción: La Nueva Galicia según las visitas de oidores (1606-1616)"(Romero y Weigand 2000). A través de los oidores, en este artículo pretende contrastar la visión de un mundo que es conquistado frente al nuevo mundo que sucumbe. Por otro lado, el texto de "Una consideración de los umbrales etnográficos y las enfermedades epidémicas en el Nuevo Mundo: Un estudio de caso de la expedición de Verrazzano en $1523 " .{ }^{2}$ (Weigand 2003). En este ensayo, apunta las características metodológicas de contrastar los datos etnográficos tempranos con la información arqueológica; lo que lleva al umbral etnográfico (etnografic base line) para el momento de contacto en el siglo XvI. A su vez, en "Sensacionalismo y etnografía: el caso de los huicholes de Jalisco" (Weigand y Fikes 2004) donde comentan que el fervor hacia ciertas prácticas huicholes produce cierto sensacionalismo lo que provoca que se falsifique el patrimonio huichol. Con ello, los autores coinciden en que a través de un trabajo etnográfico concienzudo se puede llegar a conformar el registro bien documentado y corregido. Por último, "Los antecedentes mesoamericanos de los murales Kiva de los hopi de Awatovi, norte de Arizona: Análisis y escenario" (Weigand 2004) constituye otro de los artículos de carácter etnohistórico donde relaciona el suroeste de Estados Unidos y el Occidente de México. A través de dos argumentos desmitifica ciertas influencias de la zona poblana-mixteca y de la Tradición Aztatlán en los contextos arqueológicos de la región central de Jalisco que sirve de replanteamiento a los contactos entre estas culturas antes y después de la conquista.

El último artículo que escribió el doctor Weigand, que de hecho inauguró la sección de "Notas y debates", en el número 126 de Relaciones, lleva por título "Para poner en contexto el estudio de Catherine Merridale, Ivan's War: Life and Death in the Red Army, 1939-1945" (Weigand 2011). El texto, basado en el estudio de Me-

${ }^{2}$ Premio al mejor artículo del periodo de la Colonia por parte del Comité Mexicano de Ciencias Históricas en el año 2003. 
rridale, se acerca a una forma de antropología histórica sobre el soldado ruso en el transcurso de la Segunda Guerra Mundial.

Phil Weigand, altruista de corazón, maestro de varias generaciones de arqueólogos, antropólogos y etnohistoriadores, padre de familia, amigo, quien siempre te saludaba con una sonrisa expresiva de amistad y de apoyo; dispuesto a platicar sobre los temas más escabrosos porque era un erudito de todo tema y materia, le encantaba leer y aprender de la gente, hombre gentil y benefactor de la tierra que lo acogió como su propio hijo, el legado que nos deja el doctor es grande, su trabajo va más allá de lo que ahora vemos, por lo que su influencia en las nuevas generaciones se autorreplicará y constituirá una vertiente de conocimiento como lo que fue y será: Un antropólogo del siglo XXI.

Gracias por todo Phil, quedamos en deuda contigo.

'Mi meta profesional era ser un antropólogo - no un arqueólogo, ni un etnólogo, ni un etnohistoriador, sino las tres cosas al mismo tiempo-"(Weigand 1992).

\section{REFERENCIAS}

Beekman, Christopher, Phil Weigand y John J. Pint, "El Qanat de la Venta: sistemas hidráulicos de la época colonial en le centro de Jalisco", en Relaciones. Estudios de Historia y Sociedad, vol. XVI, verano-otoño, núms. 63/64, 1995, 139-185.

Romero, José Manuel y Phil Weigand, "El fin de un mundo y la formación de uno nuevo. Ensayo-reseña de sociedades en contrucción: La Nueva Galicia según las visitas de oidores (16061616)", en Relaciones. Estudios de Historia y Sociedad, vol. XXI, otoño, núm. 84, 2000, 273-284.

Weigand, Phil, "Introducción”, en Ensayo sobre el Gran Nayar: entre coras, huicholes y tepehuanes, México, Instituto Nacional Indigenista, CEMCA, El Colegio de Michoacán, 1992. , Evolución de una civilización prehispánica, El Colegio de Michoacán, Zamora, 1993.

, "La antigua ecúmene mesoamericana: "un ejemplo de so- 
breespecialización", en Relaciones. Estudios de Historia y Sociedad, vol. XXI, primavera, núm. 82, 2000, 39-58.

"Una consideración de los umbrales etnográficos y las enfermedades epidémicas en el Nuevo Mundo. Un estudio de caso de la expedición de Verrazzano en 1523, en Relaciones, vol. xxiv, verano, núm. 95, 2003, 236-266.

"Los antecedentes mesoamericanos de los murales Kiva de los hopi de Awatovi, norte de Arizona: Análisis y escenario", en Relaciones. Estudios de Historia y Sociedad, vol. xxv, otoño, núm. 100, 2004, 313-342.

"San Aguebaud, Claudius y la arqueología", en Relaciones. Estudios de Historia y Sociedad, vol. xxIx, invierno, núm. 113, 2008, 177-206.

"Para poner en contexto el estudio de Catherine Merridale, Ivan's War: Life and Death in the Red Army", en Relaciones. Estudios de Historia y Sociedad, vol. xxxII, primavera, núm. 126, 2011, 205-222.

Weigand, Phil y Acelia García de Weigand; Tenamaxtli y Guaxicar: las raices profundas de la rebelión de Nueva Galicia, Zamora, El Colegio de Michoacán y Secretaría de Cultura del Estado de Jalisco, 1996.

Weigand, Phil y Eduardo Williams, "Adela Breton y los inicios de la arqueología en el occidente de México", en Relaciones. Estudios de Historia y Sociedad, vol. xviII, primavera, núm. 70, 1997, 127-256.

Weigand, Phil y Jay C. Fikes, "Sensacionalismo y etnografía: el caso de los huicholes de Jalisco" en Relaciones. Estudios de Historia y Sociedad, vol. xxv, primavera, núm. 98, 2004, 49-68.

Weigand, Phil, Chris Beekman y Rodrigo Esparza, Tradición Teuchitlán. El Colegio de Michoacán, A.C. y Secretaría de Cultura de Jalisco. 2008. 